\title{
La diversidad geolingüística en el diccionario monolingüe: afinidades y discrepancias en las lexicografías española y francesa
}

\author{
José Luis Aliaga Jiménez \\ Universidad de Zaragoza
}

\section{INTRODUCCIÓN}

Entre las muchas cuestiones problemáticas que se le plantean en la actualidad a la práctica lexicográfica nos ha preocupado especialmente, en el curso de nuestros trabajos, el modo en que aquélla ha afrontado y afronta la diversidad geolingüística en el seno del llamado diccionario monolingüe. Es conocida la extraordinaria variación geográfica que, en comparación con otros niveles de análisis lingüístico, presenta el léxico, el cual constituye el objeto de atención preferente, aunque no exclusivo, de la lexicografía.

Así pues, no es de extrañar que la variación espacial del léxico constituya, por una parte, un tema recurrente y siempre abierto en los planteamientos teóricos y, por otra, un escollo permanente para una práctica que quiere dejar atrás los rígidos esquemas normativos tradicionales y se proclama, cada vez con mayor insistencia, descriptiva. Sin embargo, no todas las corrientes teóricas se han ocupado igualmente de la variedad interna de la lengua ni todas se muestran igualmente aptas para ofrecer una explicación y un tratamiento diccionarístico adecuado de ésta. Por lo general, los modelos lingüísticos formales, relacionados o no con el procesamiento del lenguaje natural, no han integrado la variedad intralingüística en su componente léxico-semántico, con independencia de cómo se haya denominado (diccionario, lexicón, etc.) y aunque se haya presentado expresamente, en ocasiones, como una alternativa real al diccionario tradicional ${ }^{1}$.

1 Vid. D. y P. Corbin (1991). En relación con estos planteamientos, pero desde una perspectiva más amplia, puede afirmarse que el encasillamiento de toda actividad lexicográfica en la lingüistica aplicada propicia con frecuencia el olvido, cuando no el rechazo, de determinados recursos ligados a la lexicografía tradicional, incluidas las ma- 
No se niega, por supuesto, el papel de la lingüística en la búsqueda de soluciones a las deficiencias de los diccionarios. Pero entendemos que el marco general desde el que interpretar y renovar la lexicografía (al menos la destinada al usuario no lingüista) debe incorporar factores que pongan de relieve el carácter del diccionario como manifestación cultural de la sociedad. La consideración de estos factores resulta especialmente relevante en el tratamiento lexicográfico de la diversidad geolingüística, tal como señaló $\mathrm{A}$. Rey, impulsor del concepto de diccionario cultural, quien ha llegado a afirmar que el estudio de este aspecto constituye "un des objets essentiels de la métalexicographie", ya que "mobilise de nombreuses considérations sociologiques, politiques et institutionnelles" (1987, p. 40).

Sin duda esto es así, en el terreno de la variación espacial de la lengua, en las lexicografías española y francesa, las cuales han desarrollado unas prácticas que en muchas ocasiones pudieran parecer a primera vista vinculadas, pero que rara vez han coincidido en el tiempo, en la intensidad o en la naturaleza con que se han manifestado. En principio, las condiciones de partida de ambas lenguas se presentan, a grandes rasgos, muy parecidas (idiomas neolatinos, con fragmentación dialectal en Europa e implantación en América, aunque con muy diferente peso demográfico)². Y lo mismo ocurre con los respectivos diccionarios monolingües, que surgen a finales del siglo XVII, en Francia, y principios del XVIII, en España. Aunque nuestro propósito es poner de manifiesto el estado de la cuestión en las últimas décadas del siglo XX, dedicaremos un breve espacio a exponer algunas reflexiones sobre los precedentes que nos puedan proporcionar un contexto preliminar desde el que entender más adecuadamente la situación presente.

nifestaciones actuales de ésta (definición no:formalizada, informaciones no funcionales, valoraciones socioculturales, etc.). Una cierta preferencia por el discurso realizable o predictible como principio orientador del diccionario (vid. D. Corbin, 1983 y D. y P. Corbin, 1991) en detrimento del discurso realizado (el corpus observado) quizá sea uno de los mayores exponentes de lo que venimos comentando.

2 Existen, claro está, divergencias a las que también nos referiremos (el francés es la lengua propia de otros países europeos además de Francia y posee una difusión en el continente africano sin parangón con la del español). 


\section{ASPECTOS BÁSICOS DE DOS TRAYECTORIAS CONVERGENTES}

Hace tiempo que se apuntó la discrepancia de los primeros diccionarios académicos, francés y español, ante la variación geográfica de la lengua, reflejada con cierta amplitud en el Diccionario de Autoridades $(1726-39)^{3}$ y ausente por completo del Dictionnaire de l'Académie françoise de 1694, que se mostró "impitoyable aux régionalismes"4. Menos conocida es la postura mantenida al respecto por los dos repertorios monolingües anteriores al de la Academia francesa, esto es, el Dictionnaire universel de A. Furetière (1690) y el Dictionnaire françois de C. P. Richelet (1680). Del estudio de las marcas de uso en este último, se desprende, a juicio de L. Bray, lo infundado de las imputaciones de purismo que recibió el diccionario de Richelet, quien, según el citado autor, se mostró receptivo con la diversidad interna del francés y, concretamente, con su diversidad geográfica5. A pesar de ello, en el Dictionnaire françois, el número de voces con indicaciones de restricción geográfica es muy inferior al del Diccionario de Autoridades ${ }^{6}$. En todo caso, más allá de la mera cuantificación, interesa subrayar otros hechos significativos:

1) Ante todo, el Diccionario de Autoridades sobresale frente a los diccionarios franceses de la época, no sólo ante el de Richelet, por la inclusión de voces americanas7, ausentes por completo en la primera lexicografía francesa monolingüe. Se trata de una circunstancia sintomática que evidencia actitudes lingüísticas y lexicográficas divergentes, que resulta particularmente reveladora, incluso considerando que el asentamiento estable de emigrantes de origen francés en América fue posterior y menos numeroso que el de población española (y, en consecuencia, que se demoró más la difusión y el desarrollo autónomo de la lengua).

3 Vid. S. Gili Gaya (1963) y F. Lázaro Carreter (1972).

4 Vid. A. Rey (1970), p. 171.

5 Vid. L. Bray (1990), p. 53. Para una visión más amplia de la época puede consultarse el volumen de la revista Lexique $(9,1990)$, dedicado a las marcas de uso en los diccionarios franceses de los siglos XVII y XVIII. En el estudio de A. Rey (1990a) incluido en este número, se analizan las marcas de uso en Furetière y el de la Academia Francesa puede consultarse Ch. Girardin (1987), pp. 77-81.

${ }^{6}$ Sobre un conjunto de 3.167 entradas (letra P del repertorio de Richelet), se localizan 38 marcadas diatópicamente -el 1,2\% del total del diccionario- (vid. L.Bray, 1990, p. 50). Por su parte, en el Diccionario de Autoridades se contabilizan 1.400 entradas con marca geográfica -el 3,7\%-(vid. A. Salvador, 1985, p. 127).

7 Vid. J. Gútemberg (1984), pp. 41-66." 
2) En segundo lugar, la riqueza tipológica de las marcas geográficas en el Diccionario de Autoridades (más de veinticinco distintas) ${ }^{8}$, contrasta con la parquedad del repertorio de Richelet, en el que una indicación genérica es casi la única (provincial, dans les Provinces)9.

3) Por último, la marca geográfica en Richelet conlleva siempre un contraste expreso con el uso parisino, mientras que en el Diccionario de Autoridades es desconocida una fórmula equivalente y el uso madrileño llega a figurar con su propia marca restrictiva, si bien en un reducido elenco de voces ${ }^{10}$. En el Diccionario de Autoridades se practicó, bien es cierto, la denominada sinonimia geográfica ${ }^{11}$, es decir, el contraste de diversos usos regionales, como en el siguiente ejemplo: "adaguar. v. a. Lo mismo que dar de beber al ganado. Voz provincial de Aragón, que en Castilla se dice abrevar". Este recurso lexicográfico presenta en el primer diccionario académico unos rasgos poco definidos (cabe dudar de la existencia de una verdadera contraposición) y afectó a un mínimo número de entradas de entre las restringidas geográficamente ${ }^{2}$. De todos modos, ejemplos como el anterior no pueden equipararse a los que aduce L. Bray, como el de paisseau "ne se dit que dans les Provinces, \& en sa place on dit à Paris échalas", o el de papin "mot vieux \& provincial au lieu duquel à Paris on dit bouillie" (Bray, 1990, p. 50). La aparente neutralidad de estos enunciados no puede ocultar el hecho básico de la marginalidad del francés no parisino. Por todo ello, aun teniendo presentes las coordenadas culturales de la época, sorprenden, en cierta medida, las palabras de L. Bray, que quizá fuerza la interpretación en su intención de presentar a Richelet como lexicógrafo ecuánime y alejado del purismo que se le atribuía:

Dans la majorité des cas, on observe l'opposition explicite du français de Paris aux français des provinces, mais, nulle part, il n'y a prescription: Richelet se fait témoin de l'usage: il constate l'existence parallèle de deux réalités linguistiques et les décrit sans prendre parti (Bray, 1990, p. 50).

Desde los primeros diccionarios monolingües franceses y españoles

8 Vid A. Salvador (1985), pp. 113-127.

9 Vid L. Bray (1990), p. 50.

10 Vid. A. Salvador (1985), p. 117

11 Vid. G. Salvador (1980), p. 52

12 Vid. J. L. Aliaga (1994), pp. 57-64 
hasta las últimas décadas de este siglo (y hasta la actualidad, en buena medida) la cuestión, teórica y práctica, de las relaciones entre la variación espacial de la lengua y la lexicografía se ha planteado únicamente en términos de valorar la oportunidad de la presencia de regionalismos en los diccionarios llamados generales. Con la llegada de la investigación teórica a la lexicografía se han hecho explícitas las restricciones normativas a que ha estado sujeta históricamente la selección del vocabulario operada en el conjunto de la lengua por los repertorios monolingües. Entre esas restricciones ha desempeñado un papel esencial la acotación geográfica de la lengua considerada común. Todavía recientemente A. Rey sostenía que, para el francés contemporáneo,

les variantes géographiques sont extraordinairement sous-traitées par les dictionnaires généraux, tous plus ou moins parisiens. L'ouverture des nomenclatures aux français régionaux, aux éléments lexicaux fonctionnant de manière significative dans une partie des populations francophones, est à peine esquissée (A. Rey, 1983a, p. 22)13.

Con anterioridad, en su excelente estudio sobre los diccionarios franceses modernos, J. Rey-Debove sólo se había interesado por el léxico regional en cuanto posible factor de desestructuración del núcleo léxico que conforma la macroestructura y, aun así, concluye que "le mot régional en tant que tel est rare à la nomenclature des dictionnaires français, et joue un faible rôle dans les divergences de nomenclature" (1971, p. 92).

Ya en 1994, la misma autora sintetizó el panorama de la lexicografía moderna apuntando que uno de los hechos más destacados de los diccionarios franceses de los últimos años ha sido la aparición en ellos de voces propias de otros países francófonos, pero no de los regionalismos franceses internos, peor representados ${ }^{14}$. Pero, considerando el punto de partida en la lexicografía francesa y la comparación con los diccionarios españoles, el avance notable que señala Rey-Debove se reduce, numéricamente a un cambio de orientación simbólico. Por ejemplo, A. Rey, que ha subrayado el esfuerzo por incorporar regionalismos en la segunda edición, dirigida por él, de Le grand Robert de la langue française ${ }^{15}$-repertorio de nomenclatura similar a la del DRAE, pero de microestructura mucho más rica en informaciones-, llega a computar veinticuatro voces

${ }^{13}$ Consúltese también A. Rey (1986), p. 34.

14 Vid. J. Rey-Debove (1994), p. 35.

15 Vid. A. Rey (1990b), p. 1837. 
y acepciones regionales en la sección comprendida entre las letras $A$ $A G R^{16}$. Baste decir que suman aproximadamente seiscientas las que se encuentran en la misma cala, en la vigésima primera edición del DRAE (1992). Es patente, pues, la timidez con que la lexicografía francesa da cabida al léxico regional que sigue entendiéndose, a pesar de todo, como un elemento desestructurador del diccionario: "il faudra se demander jusqu'où pourront aller les dictionnaires hexagonaux sans rompre un équilibre fragile" (J. C. Boulanger, 1985, p. 128). Es más, la apertura a los particularismos de Bélgica, Suiza o Quebec y, bastante después, a los del francés de África, encuentra, primero, una explicación en términos económicos (“d'abord pour des raisons commerciales") ${ }^{17}$, en un intento de penetrar en el mercado del resto de países francófonos y en el contexto de una fuerte competencia editorial.

No se entienda, sin embargo, que con las comparaciones anteriores se ha querido sugerir que la introducción intensiva de voces regionales en los diccionarios generales, como ocurre en los españoles, representa la solución idónea al reto de construir repertorios representativos de la variedad

16 Vid. A. Rey (1986), p. 37. La integración de regionalismos en la nomenclatura del resto de los principales diccionarios generales franceses es francamente exigua. Así , por ejemplo, en el Grand Larousse de langue française (Paris, Larousse, 1971-78), en el Lexis. Dictionnaire de la langue française (Paris, Larousse, 1975) o en el Petit Robert (Paris, Le Robert, 1992). Por las propias características del diccionario, son más abundantes los regionalismos -todos ellos de extracción literaria- en el Trésor de la Langue Française. Dictionnaire de la langue du XIX et du XX $X^{e}$ siècle (16 vols., Paris, Klincksieck-C.N.R.S, 1971-1994), aunque en una cantidad muy inferior a la de, por ejemplo, la última edición (1992) del diccionario de la Real Academia Española (DRAE). Vid. J.Y. Dugas (1983), p. 641. A todos ellos se suma el hecho de que, al igual que en el diccionario de Richelet, los recursos metalingüísticos (marcas de uso) de los repertorios franceses se reducen en la práctica a las abreviaturas dial. o dialect. (dialectal), y région. (regional). Asimismo -y esto es común con el $D R A E-$, la información sobre los regionalismos contraviene frecuentemente los príncipios de normalización del artículo lexicográfico (vid. Rey-Debove, 1971, p. 173), y se integra en él de modos diversos, como en los siguientes ejemplos tomados de la edición de 1992 de Le Petit Robert: "bleuet [...] 20 (1615; bleue adj., 1609). Au Canada, Baie bleue de l'airelle des bois, ou myrtille d'Amérique [...]"; "aubette [...] Région. (Belgique, Ouest de la France). Abri édifié sur la voie publique [...].

17 Vid. A. Rey (1986), p. 34. Véanse también A. Rey (1983b), p. 552 y J. C. Boulanger (1985), p. 142. Debe apuntarse que, en el tema que nos ocupa, el aspecto comercial apenas ha sido motivo de cambios sustanciales en la práctica lexicográfica española (vid. infra, nota 48). 
espacial de la lengua (variedad que, en los casos aquí examinados, se presenta también en el nivel estándar). Pero sí es cierto que, en parte, la lexicografía francesa actual ha terminado aceptando como mal menor el procedimiento que en los diccionarios españoles se viene aplicando desde el Diccionario de Autoridades. Y éste se basa en la idea de que la acumulación de regionalismos repercute en beneficio de una descripción más acorde con la lengua real. De este modo se opta por lo que podría denominarse una rectificación cuantitativa de la práctica diccionarística (incremento progresivo de voces regionales) en detrimento de una transformación cualitativa (de la que se tratará más abajo). Se trata, pues, de legitimar el modelo de diccionario o, al menos, de paliar el juicio normativo que pesa sobre la extracción geográfica del léxico.

En definitiva, en este punto, las trayectorias lexicográficas española y francesa han representado las dos opciones básicas del mismo programa lexicográfico. Puede decirse que la actitud de la lexicografía en Francia y en España ante la pluralidad de la lengua coincide en sus rasgos fundamentales y difiere en el modo en que se ha llevado a la práctica. La proliferación de censuras de uso (marcas geográficas) en los diccionarios españoles, especialmente cuando se refieren al español de América, no ha contribuido a ampliar la representación de la base común de la lengua, sino a poner de manifiesto la parte considerada subordinada. Por su parte, la lexicografía francesa ha recurrido tradicionalmente al método más sutil y radical de la exclusión de toda otra variedad de francés que no fuera la localizada en la región parisina, aunque últimamente se haya producido una leve inclinación hacia el método practicado en España.

\section{DE LA LEXICOGRAFÍA SUBSIDIARIA A LA LEXICOGRAFÍA INTEGRAL}

La existencia de una similar actitud histórica ante las variedades geográficas de la lengua no privilegiadas por la lexicografía se refuerza al comprobar la presencia en la lingüística francófona de alguno de los lugares comunes acuñados a propósito del español de América. Así, por ejemplo, la imputación de arcaísmo al francés belga ${ }^{18}$, el indigenismo del

18 Vid. F. Massion (1987), p. 71 y R. Andrianne (1984), p. 9. 
francés canadiense, el problema de la mayor receptividad ante los préstamos de lenguas extranjeras, la presunta proliferación de vicios e incorrecciones en las modalidades laterales o, incluso, la justificación del mantenimiento de la normatividad establecida por quienes auguraban el riesgo de fragmentación lingüística ${ }^{19}$. En terreno específicamente lexicográfico las afinidades se concretan en la amplia difusión de las recopilaciones de regionalismos bajo el título de diccionario de expresiones o locuciones viciosas, de dificultades, de barbarismos, etc. (vid. infra, nota 23); en las recomendaciones para que los diccionarios en Francia se abran únicamente a los regionalismos de extensión suficientemente amplia $^{20} ; \mathrm{y}$, consecuentemente, en la equiparación lexicográfica entre los regionalismos internos de Francia y las voces y acepciones de difusión general en los demás países francófonos ${ }^{21}$.

Por otro lado, en relación con el tema que nos ocupa asistimos en los últimos años a una lenta renovación del panorama lexicográfico y al nacimiento de diccionarios planteados como alternativa a la lexicografia del regionalismo. En el caso del español las innovaciones se están desarrollando en Hispanoamérica y para las modalidades americanas de la lengua. No ocurre exactamente igual, como se verá, respecto del francés norteamericano, para el que existen iniciativas que llegan desde Europa. Pero antes de atender esta cuestión cabe referirse a una particularidad que no concurre en el caso español: la lengua francesa también es la lengua originaria y oficial de dos países europeos, con un desarrollo económicocultural y con unas instituciones político-administrativas semejantes a los de Francia, factores de interpretación básicos en una comprensión del diccionario como producto intrínsecamente sociocultural 22 .

19 Vid. A. Valdman (1983), p. 700. Para el español pueden consultarse los estudios de J. M. Lope Blanch (1969), (1972) y (1987). Asimismo, con datos contrastados, al igual que para el español de América, también se han investigado los orígenes dialectales del francés quebequense. Véase, por ejemplo, la contribución de J. P. Chauveau y T. Lavoie (1993).

${ }^{20}$ Vid. F. Massion (1987), pp. 62-63.

21 Vid. F. J. Hausmann (1986), pp. 3-4 y (1990), p. 1500.

22 No nos referiremos aquí a la lexicografía del francés de los diversos territorios del continente africano, o de las Antillas, ni a los diccionarios de lenguas criollas de base francesa. Para todo ello pueden consultarse los estudios de F. J. Hausmann (1986 y 1990) y A. Bollée (1991). En concreto, la presencia del francés en varios países africanos como segunda lengua, utilizada con frecuencia, aunque sólo en ciertos niveles de uso (política y administración, sobre todo), plantea a la lexicografía de lengua unos problemas que no conoce el español, salvo, quizá, por la reducida presencia del español en Guinea Ecuatorial o en el Antiguo Sahara español. Sobre el español en estas zonas veán- 
Aunque estos condicionantes parecen más favorables que los existentes en Hispanoamérica para el surgimiento de una lexicografía general propia, la lexicografía de expresión francesa en Bélgica o en Suiza no ha logrado superar la atracción que el normativismo parisino ejerce sobre el conjunto del francés, que, en su manifestación más extrema, conduce a la identificación con toda la lengua histórica de la lengua culta de "l'Ilede-France", que algunos denominan français central o, incluso, français universel23. Es fácil entender que, en este contexto, el único tipo de diccionario posible sea el de carácter diferencial y contrastivo respecto del francés de Francia. Las interesantes apreciaciones de R. Andrianne nos presentan a un hablante cultivado belga incómodo con su propia lengua ("inconfort linguistique"), que hace de ella objeto de debate constante, y ante la cual adopta dos actitudes contrarias: "d'une part le purisme le plus rigoureux, le souci du beau langage [...]. Par ailleurs [...] l'affirmation de l'appartenance belge dans une langue incorrecte, provinciale ou provocante" (R. Andrianne, 1984, p. 9.)24. F. Massion, por su parte, reclama la consideración del francés de bélgica como variante nacional del francés -y el abandono de su consideración como variante regional-, al mismo tiempo que traza las líneas maestras de lo que debería ser un futuro diccionario del francés de Bélgica, que considere la variedad belga como una modalidad en pie de igualdad con el resto de las variedades nacionales del francés ${ }^{25}$.

se los trabajos de J. M. Lipski (1985) y P. Tarkki (1995).

23 Vid. J. C. Corbeil (1984), p. 32. Para R. Andrianne le "français universel" est une vision de l'esprit et le "français central", qui se confond avec Paris, est insaisissable" (R. Andrianne, 1984, p. 11). Esta concepción de la lengua se halla en correlación, en Bélgica, con un tipo de trabajos normativos muy difundidos, en los que las particularidades del francés belga son tratadas como vicios o desviaciones de la lengua (chasse aux belgicismes). Recientemente esta orientación se ha suavizado, aun sin salir de su tendencia normativista, y el objetivo se ha transformado en la recolección del léxico específico que el francés de Bélgica puede aportar al denominado français central (belgicismes de bon aloi). Vid. R. Andrianne (1984), p. 5 y F. Massion (1987), pp. 57-84. El proceso es paralelo al que se comprueba en el mundo hispánico con la publicación de multitud de trabajos dedicados a "la cacería de incorrecciones, barbarismos y vicios de nuestras variedades regionales, sobre la base de su comparación con el español de Castilla" (vid. L. F. Lara, 1991, pp. 84-85). Véase asimismo R. Werner (1991), pp. 235-236.

${ }^{24} \mathrm{Y}$ en otro lugar afirma: "Les Belges sont prêts à accepter les mots auvergnats ou aquitains, provinciaux aux yeux des parisiens, et à refuser les leurs. On saisit ici l'importance de la frontière politique dans la conscience linguistique des Belges" (R. Andrianne, 1984, p. 11).

25 Vid. F. Massion (1987), pp. 59 y $72-76$. 
La principal coincidencia de las lexicografías francesa y española se encuentra en el foco desde el que se está contribuyendo a la renovación de las respectivas tradiciones diccionarísticas, esto es, a su transformación cualitativa (vid. supra) al menos en lo tocante al tratamiento de la norma y de la variación lingüísticas. En este sentido, si el camino emprendido por L. F. Lara en El Colegio de México con el Diccionario del español de México marca la pauta en la renovación de la lexicografía monolingüe española, las propuestas teóricas y las realizaciones concretas llevadas a cabo para Quebec -no siempre en Quebec-, sobre todo en las últimas dos décadas, representan el equivalente en la lexicografía francesa ${ }^{26}$. No obstante, en Quebec se superpone el hecho de que la lexicografía y la metalexicografía se desenvuelven condicionadas por un contexto donde la lengua francesa constituye un argumento clave de reivindicaciones políticas, lo cual, a su vez, determina el control de organismos oficiales sobre la lengua (Office de la langue française, creada en 1961), con objetivos diversos ligados a la normalización $\mathrm{o}$, mejor, al aménagement linguistique27.

No obstante, por encima de estas diferencias hay que subrayar el fondo común compartido por los proyectos lexicográficos mexicano $\mathrm{y}$ quebequense, imbuidos, a su vez, de los principios que inspiraron a $\mathrm{N}$. Webster para la publicación en 1828 del American Dictionary of the English Language ("lo que se le pide al DEM [...] es que al cabo de los años llegue a tener el papel de «un Webster mexicano»"28). Esto es, el abandono de la idea de la lengua como uso desviado respecto de un modelo europeo y el deseo de vincular el diccionario a la sociedad en la que surge. Todo lo cual exige una labor previa de indagación, reflexión e interpretación de las creencias y actitudes sobre la lengua y del senti-

${ }^{26} \mathrm{Si}$ la lengua y la lexicografia quebequenses han pasado por los estadios descritos para Bélgica y Suiza (vid. C. Poirier, 1986, pp. 271-274 y J. D. Gendron, 1986, p. 90), hoy en día la lexicografía de la región canadiense sirve de modelo para los países europeos citados. Vid. R. Andrianne (1984). Para Suiza véase el trabajo de C. Fréchet y J. B. Martin (1993).

27 Según lo interpretan los propios autores quebequenses aménagement no equivale exactamente a normalización o a planificación. Vid. D. Daoust y J. Maurais (1987). Aunque existen problemas compartidos (presión del inglés -en diferentes planos-, lenguas indígenas, etc.), la situación difiere sustancialmente de la de México, donde el principal conflicto sin resolver viene dado por la existencia de un conjunto numeroso de hablantes de lenguas indígenas, y donde el único organismo oficial encargado de diseñar y aplicar una política lingüística para el español apenas tuvo actividad. Vid. L. F. Lara (1993).

28 Vid. L. F. Lara (1990), p. 111. 
miento de la norma lingüística de los hablantes a los que va dirigida la obra $^{29}$. Ésta es, precisamente, la vertiente lexicográfica de los objetivos del aménagement linguistique: la búsquểa de un consenso social en relación con un proyecto lingüístico colectivo (que contrasta con las connotaciones de intervencionismo o inadaptación de los términos planificación y normalización $)^{30}$.

Todo ello no ha sido ajeno al cuestionamiento de las relaciones de dependencia entre la pluralidad de usos de la lengua y, por lo tanto, de los conceptos y de la terminología que sustentaban tales relaciones. Así, en el caso francés han sido ampliamente discutidos y repensados los conceptos de français standard-central, commun-, que encerraban, en realidad, como ya se ha apuntado, la referencia a una variedad lingüística muy reducida, opuesta al resto, que, a su vez, era denominado français régional, dialectal, latérale, etc. ${ }^{31}$. En este sentido, aparte de la crítica del concepto mismo de francés de referencia, no han faltado autores que han censurado la contribución decisiva de la lingüística estructuralista como sustento teórico de la jerarquía français standard-français régional:

Dans ce modèle, la pertinence sociale n'est pas prise en compte, de sorte que les faits linguistiques de cet ordre [regional] sont considérés comme non-pertinents et éliminés de la description (J. C. Corbeil, 1984, p. 37) ${ }^{32}$.

29 Vid. L. F. Lara (1990) y C. Poirier (1986). De acuerdo con esta idea el lexicógrafo es, ante todo, el transmisor cualificado de los usos lingüísticos en un contexto sociocultural dado: "Le défi du lexicographe contemporain consiste à répondre aux besoins concrets d'une collectivité tout en satisfaisant le mieux possible aux exigences de la linguistique" (vid. C. Poirier, 1986, p. 270). A este respecto resulta ilustrativo el rechazo social que soportó, en Estados Unidos, el Webster's Third International Dictionary of the English Language (Springfield, Merriam-Webster, 1961), debido, sobre todo, a su pretensión de convertirse en un repertorio măs descriptivo y menos prescriptivo que en la anterior edición de 1934. Vid. G. J. Forgue (1987).

30 No quiere decirse con ello que la confección de un diccionario deba apoyarse en una exploración exhaustiva para reconocer la idea que la sociedad se ha formado de su lengua. La importancia del diccionario enfocada desde su efecto creador de la norma -y no sólo como receptor de la norma- es otra perspectiva de la lexicografía cuyo debate cuenta con numerosas referencias. Véanse especialmente L. Zgusta (1989) y A. Rey (1987), p. 39.

31 Son numerosos los trabajos que abordan esta cuestión. Véanse, entre otros, los de J. C. Boulanger (1985), J. Y. Dugas (1983), A. Rey (1983b) y (1986), A. Valdman (1983), F. Massion (1987), J. C. Corbeil (1984), J. Maurais (1986), J. D. Gendron (1986) o R. Andrianne (1984). Para el español véanse, sobre todo, los de L. F. Lara (1990) y (1991).

32 También Valdman se refiere en términos similares al generativismo y al descriptivismo bloomfieldiano (vid. A. Valdman, 1983, pp. 667-668). 
En lo que se refiere concretamente a Quebec y a las condiciones sociolingüísticas que permitieron la formación de un sentimiento lingüístico autónomo (l'idèologie du dépassement) y el desarrollo de una lexicografía integral (que ya no se delimita a partir de unos usos lingüísticos externos), J. D. Gendron ha situado el punto de inflexión en los años sesenta, durante la llamada Revolución tranquila, etapa a la que habían precedido otras, caracterizadas bien por la ausencia de una conciencia lingüística definida (hasta 1800), bien por la difusión de un patente sentimiento de culpabilidad lingüística y de las reacciones puristas que lo acompañaron (1800-1960) ${ }^{33}$. Existe un acusado paralelismo entre los períodos que distingue J. D. Gendron y las etapas en que se desarrolla una lexicografía cada vez más emancipada de la variedad europea. De hecho, antes de 1800 ni siquiera es posible hallar un vocabulario de quebequismos publicado, aunque P. Potier había redactado uno. en $1750^{34}$. El hito principal de los diccionarios diferenciales-contrastivos se produce con la publicación del Glossaire du parler français au Canada (1930) por parte de la Société du parler français au Canada, fundada en 190235. Las insuficiencias del proyecto sirvieron para que se gestara en los años cincuenta el Trésor de la langue française au Québec, que desembocó, ya en 1985, en el volumen de presentación del Dictionnaire du français québécois ${ }^{36}$.

Pero nos interesan sobre todo las repercusiones lexicográficas de las nuevas actitudes ante el francés de la sociedad quebequense a partir del último período, que discurre desde 1960 hasta nuestros días. Los diccionarios de L. A. Bélisle prefiguran la lexicografía integral de los últimos años, pero sus intentos de formar un diccionario basado exclusivamente en el francés canadiense adolecieron de numerosas carencias de método y de ejecución ${ }^{37}$. El último eslabón hacia los diccionarios basa-

33 Vid. J. D. Gendron (1986). Véanse consideraciones en el mismo sentido para el español de México en L. F. Lara (1990), pp. 157-193. Por su parte, J. Y. Dugas considera la publicación del Glossaire du parler français au Canada en 1930 el momento clave para la renovación de la lexicografía en Quebec. Vid. J. Y. Dugas (1983) pp. 630-643.

34 Vid. F. J. Hausmann (1990), p. 1501.

35 Vid. J. Y. Dugas (1983), pp. 634-635.

36 Véase la descripción de M. Francard (1988). Se trata de un diccionario histórico, etimológico y diferencial -sólo se interesa por el léxico que no se halla en los diccionarios y en las gramáticas del francés de referencia (estándar, común), con independencia de que su uso en Francia esté atestiguado-, y está dirigido a un público especializado.

37 Véase lo apuntado por C. Poirier (1986), pp. 274-275 y J. Y. Dugas (1983), pp. 
dos en el francés de Quebec, como modalidad considerada en sí misma, lo representa el Dictionnaire CEC jeunesse (Montréal, CEC, 1986), repertorio de tipo escolar surgido de la adaptación del europeo Dictionnaire Hachette juniors (Pàris, Hachette, 1980). Publicado el mismo año en que C. Poirier, redactor del Dictionnaire du français québécois, se cuestionaba si la lexicografía en Quebec había madurado lo suficiente para acometer una empresa de estas características ${ }^{38}$, el Dictionnaire CEC jeunesse era el primero en distinguir mediante una marca las voces particulares del francés de Francia (francismes). Dos años más tarde, el propio C. Poirier se convertía en el redactor principal del Dictionnaire du français plus à l'usage des francophones d'Amerique (CEC, Montréal, 1988), nueva adaptación de un repertorio de la editorial Hachette (Dictionnaire Hachette de la langue française, Paris, 1987), complementado con el fondo documental del Trésor de la langue française au Québec. Ya no se trata de un repertorio dirigido a los escolares (18.000 entradas del Dictionnaire CEC jeunesse), sino de un diccionario con una macroestructura de tamaño medio (62.000 entradas), dirigido al público adulto 39 .

En 1992 se avanza un paso más con la aparición del Dictionnaire québécois d'aujourd'hui (Montréal, Dicorobert, 1992; $2^{\mathrm{a}}$ edición de 1993), dirigido por J. C. Boulanger y supervisado por A. Rey. En esta

637-639 sobre los repertorios de L. A. Bélisle, titulados Dictionnaire général de la langue française au Canada (Québec, Bélisle editeur, 1957; 2 $2^{\mathrm{a}}$ ed. 1971) y Dictionnaire nord-américan de la langue française (Montréal, Beauchemin, 1979). En una postura mucho más radical se sitúa el repertorio, también diferencial, de L. Bergeron, Dictionnaire de la langue québécoise (Montréal, VLB éditeur, 1980). Véase sobre este último la opinión de J. Y. Dugas (1983), pp. 638-640.

38 Vid. C. Poirier (1986), pp. 274-276.

39 Véase la presentación de L. Mercier (1992). La transformación de un diccionario para convertirlo en un repertorio de otra variedad lingüística parcialmente distinta es, sin duda, un camino cómodo para conseguir un diccionario integral en un breve plazo de tiempo y a un coste razonable, pero también constituye un método escasamente fiable. Véanse las críticas de M. C. Cormier (1993), p. 114, al Dictionnaire du français plus: "Dans l'ensemble, la vision qui est présentée à l'utilisateur reste toujours celle de l'Hexagone". Por ello, la posibilidad de adaptar el DrAE para confeccionar un diccionario del español mexicano fue desechada por L. F. Lara, con buen criterio, para emprender el sendero más arduo, pero más satisfactorio a largo plazo, de la construcción del Corpus del español mexicano contemporáneo (vid. L. F. Lara, 1990, pp. 112 y sigs.). Esta elección, por otro lado, evitó la presencia constante, como telón de fondo, de una variedad de referencia externa a la propiamente analizada y, por lo tanto, la necesidad de marcar los peninsularismos o españolismos, como ocurre con los francismes en los diccionarios quebequenses (vid. infra). 
ocasión la obra adaptada es el Micro-Robert, y, por lo tanto, se trata de un diccionario de aprendizaje pero destinado a un público de edades diversas (40.000 entradas). Sin embargo, se llevan más lejos las soluciones apuntadas por el Dictionnaire du français plus (transcripciones fonéticas conformes a la modalidad lingüística de referencia, ejemplos tomados de la realidad quebequense, etc.). Sobre todo, la orientación más descriptiva determinó la selección de un léxico quebequense que no se limitaba al estrato estándar -como su predecesor-, sino que acopiaba materiales de niveles de lengua populares e, incluso, vulgares. Este hecho desencadenó una viva polémica en el seno de la sociedad quebequense, dentro de la cual ya se habían levantado voces en contra del Dictionnaire du français plus, mucho más comedido ${ }^{40}$.

Queda por mencionar, tan sólo, el diccionario del francés hablado en Quebec de N. Beauchemin et alii (Dictionnaire de fréquence des mots du français parlé au Québec: fréquence, dispersion, usage, écart réduit, New York, Peter Lang, 1992). No se trata de un diccionario de lengua sino de la presentación de los materiales obtenidos del análisis estadístico de un corpus de, aproximadamente, un millón de ocurrencias (la mitad que en el Corpus del español mexicano contemporáneo). Aunque se anuncia como un repertorio de la lengua oral donde los textos se dividen en diez estratos -de mayor a menor grado de espontaneidad-, en buena parte los datos se han tomado de géneros literarios asimilados al nivel hablado (textos leídos en la radio o en la televisión, telenovelas, obras de teatro). El conflicto respecto de la norma lingüística que debe auspiciarse oficialmente en Quebec alcanza incluso a este trabajo del que no están

40 Para una descripción del Dictionnaire québécois d'aujourd'hui y de la polémica que suscitó, consúltese M. Cormier (1993). Aparte de la variedad lingüística en la que se basa, ofrecen especial interés los esfuerzos por eliminar del diccionario-en definiciones y ejemplos, sobre todo-, los estereotipos étnicos, sexistas o religiosos (vid. M. Cormier, 1993, pp. 118-120). Los autores actuaron apremiados por las directrices del ministerio de educación de Quebec (MÉQ) que analiza minuciosamente este aspecto, entre otros, en las obras de orientación escolar. Todo ello afectó, a su vez, a la edición norteamericana de Le Robert junior illustré (Paris, Le Robert, 1994). Este repertorio contiene unas 20.000 entradas y se dirige a un público escolar de menor edad que el perseguido por el Dictionnaire québécois d'aujourd'hui. La selección del léxico y su tratamiento en Le Robert junior illustré evidencian una moderación frente a las opciones mucho más audaces y controvertidas del repertorio anterior, respecto del cual supone un cierto retroceso, hecho del que no están ausentes las consideraciones comerciales ante la posibilidad de ser rechazado por el MÉQ. Vid. la reseña de Le Robert junior illustré a cargo de J. C. Boulanger y J. De Blois (1995). 
ausentes consideraciones normativas, por ejemplo, en la valoración de los préstamos del inglés.

Las reacciones suscitadas, sobre todo, tras la publicación del Dictionnaire québécois d'aujourd'hui, ponen de manifiesto que la política de aménagement, la promoción de una norma quebequense del francés, dista de ser aceptada por la mayoría de la sociedad, al menos, por la parte más conservadora de ésta. El prolongado sentimiento de inseguridad linguística de la sociedad quebequense explica, en buena parte, la respuesta mayoritaria de oposición a un diccionario que, en principio, se ajustaba a los objetivos que se había marcado la política de la lengua en Quebec: “on peut en effet se demander si ce rejet du dictionnaire n'équivaut pas à un rejet de leur propre modèle de langue" (M. C. Cormier, 1993, p. 126). La vuelta a posiciones anteriores representada por Le Robert junior illustré ha suscitado el temor a las medidas de revisionismo lingüístico por parte de la administración, que se ha mostrado sensible a las opiniones de quienes, lejos de admitir la plurinormatividad de la lengua francesa, desean preservar y fomentar la norma idiomática proveniente del otro lado del Atlántico.

Este conciso panorama nos muestra, en los aspectos tratados, una lexicografía francesa sorprendentemente próxima a la lexicografía hispánica, y no sólo a la peninsular. Si dejamos de lado los primeros diccionarios monolingües, en los que la lexicografía española, considerada en su contexto histórico, se muestra bastante más abierta a la diversidad de usos de la lengua, la práctica lexicográfica actual descubre dos tradiciones diccionarísticas divergentes en sus soluciones pero coincidentes en las ideas lingüísticas en que se apoyan. No obstante, hay que notar que la lexicografía francofrancesa, cuando ha tratado de presentarse en los últimos años con una imagen más abierta o sensible hacia los usos regionales, se ha decidido por la adopción de una postura convergente, aunque mucho más restrictiva en términos cuantitativos, con la aplicada por los diccionarios españoles monolingües desde sus inicios. Por otra parte, en la confección de diccionarios que se hacen eco de una norma geográfica distinta de la transmitida habitualmente se ha tomado como base la modalidad de los ámbitos a los que las respectivas lenguas habían sido exportadas (en el caso del francés cabía la posibilidad de que Bélgica o Suiza hubieran tomado la iniciativa). Pero también aquí cabe apreciar algunas diferencias. Para el francés, los lexicógrafos europeos han desempeñado un papel relevante en el estudio y elaboración de propuestas concretas en relación, sobre todo, con Quebec. Asimismo, varios de 
los productos lexicográficos mencionados más arriba, elaborados específicamente para el mercado norteamericano, han sido confeccionados por editoriales cuya sede central se encuentra en Francia (Hachette y Le Robert) ${ }^{41}$. Por el contrario, en la lexicografía teórica producida en España son escasísimas las referencias a esta cuestión y no existe ningún diccionario similar, por ejemplo, al Dictionnaire québécois d'aujourd'hui (ni, según nuestros datos, tampoco ningún proyecto) ${ }^{42}$.

No cabe duda de que, en el caso francés, ha intervenido el factor comercial (la mayoría de las ocasiones decisivo en lexicografía) y de que las editoriales han sabido dar respuesta con cierta diligencia a lo que se reclamaba desde nuevas posturas lingüístico-lexicográficas. Pero quizá todo ello haya ocasionado también alguna consecuencia no prevista. $\mathrm{La}$ adaptación de diccionarios europeos, preferida hasta el momento para el francés quebequense, puede encontrarse detrás del rechazo de algunos productos (vid. supra), circunstancia ésta que ha sorprendido incluso a los propios impulsores del aménagement linguistique. Así, en relación con Quebec se ha puesto el acento en la consecución de diccionarios en los que los usos presentados como desviados fueran aparentemente los privativos del francés de Francia. Sin querer establecer - pero tampoco rechazar- una relación directa con la reacción social a la que nos hemos referido, lo cierto es que desde un punto de vista lexicográfico y lingüístico el recurso de marcar los francismes perpetúa la evocación omnipresente de la norma europea. Quizá la orientación del diccionario estadístico del francés hablado en Quebec de N. Beauchemin marque un nuevo rumbo de la lexicografía en la región canadiense.

En consecuencia cabría valorar como más idóneo el camino empren-

41 Incluso en los preliminares de algún diccionario destinado al mercado europeo se estimula la realización de repertorios específicos de las diversas variedades del francés:

La description du français hors de France dépasse de loin les objectifs et les possibilités d'un ouvrage realisé à Paris. La normalisation du français, langue maternelle, parlé au Québec, en Belgique ou en Suisse, celle du français, langue officielle ou véhiculaire utilisée au Maghreb, en Afrique noire, etc. relève à l'évidence des instances souveraines des divers États (vid. A. Rey, 1992, p. XIX).

42 M. Seco abordó el asunto durante el Primer Coloquio sobre Lexicografía del Español de América (vid. M. Seco, 1988, p. 97). Puede consultarse también el trabajo de G. Haensch (1997), pp. 225-226 y, especialmente, el de J. Gutiérrez (1994). En la vertiente práctica, de los diccionarios publicados en España sólo el Clave. Diccionario de uso del español actual (Madrid, SM, 1996) ha ensayado una presentación parcialmente novedosa de la diversidad geográfica del español. Vid. J. L. Aliaga (1997). 
dido en México (con financiación pública), más pausado pero más favorable para la asimilación social de un diccionario integral que se sustenta en un corpus de datos original y rompe con actitudes ante la lengua muy arraigadas, también en la sociedad hispanoamericana ${ }^{43}$. A este respecto resultan sumamente ilustrativas las palabras con que L. F. Lara presentaba el Diccionario básico del español de México:

la obra se basa en el uso mexicano y tiene a los mexicanos como punto de referencia, por lo que no se han introducido marcas o indicaciones que permitan reconocer «mexicanismos», «americanismos» o aun «españolismos» entre los vocablos o las acepciones que la componen. Hacerlo no solamente habría acarreado el riesgo de equivocarse, debido a la falta general de estudios comparativos del léxico de la lengua española en las diferentes regiones del mundo hispánico, que permitan identificarlos con cierta seguridad y exhaustividad, sino que habría significado que la legitimidad del uso mexicano de la lengua se viera puesta en crisis al crear una «conciencia del desvío» con respecto a otro uso, distinto regionalmente pero implícitamente aceptado como ejemplar normativo (L. F. Lara, 1986, p. 15) ${ }^{44}$.

\section{SOBRE EL AUGE DE LA LEXICOGRAFÍA INTEGRAL}

No queremos terminar estas líneas sin referirnos brevemente a las condiciones en que ha sido posible el surgimiento de un modelo de diccionario monolingüe articulado en torno al tratamiento independiente de una variedad considerada subordinada durante largo tiempo por la lexicografía y la lingüística. En este sentido creemos que a este tipo de repertorio (denominado integral, nacional, etc., según los autores) le es aplicable la reflexión que apuntó A. Rey a propósito del nacimiento en Europa del diccionario monolingüe, obra originada "de la disparition d'une démar-

${ }^{43}$ Hay que decir que ya existen para otros países hispanohablantes corpus lingüísticos, preparados o en vías de elaboración, con el objetivo de confeccionar diccionarios similares al Diccionario del español de México. Son los siguientes: el Corpus integral del español de Chile, dirigido por L. Sáez Godoy; el Corpus del español peninsular, dirigido por N. Cartagena (Universidad de Heidelberg) y el Corpus del español de Bolivia, a cargo de N. Gutiérrez Marrone y C. Coello. Vid. L. F. Lara (1996), p. 24.

44 Después de dos versiones reducidas, enfocadas al público escolar, se ha publicado en 1997 el Diccionario del español usual en México (L. F. Lara, dir., México D. F., El Colegio de México), último paso para la aparición de la versión definitiva del Diccionario del español de México, prevista para 1998. 
che traductrice. Le vocabulaire décrit l'était par son aptitude à être exprimé autrement; ce critère mutilant et arbitraire -pour la réalité fonctionnelle qu'est la langue de départ- devait disparaître pour que le dictionnaire parvienne à refléter, en apparence, la réalité socio-linguistique du lexique" (A. Rey, 1977, p. 87). En sentido estricto y consideradas en sí mismas las modalidades lingüísticas de Bélgica, de Quebec, de México, de Colombia, etc., la lexicografía correspondiente ha hecho de ellas, hasta la fecha, un tratamiento bilingüe. Y ello de dos modos: 1) mediante la confección de inventarios diferenciales y contrastivos (de regionalismos, de barbarismos, de indigenismos, etc.) y 2) mediante la inserción de los respectivos particularismos (conocidos como regionalismos, dialectalismos, localismos, etc.) en los diccionarios generales. Ambas soluciones responden a una situación de plurilingüismo (intralingüístico) que se sortea a través de la traducción, a la norma considerada común, de los contenidos lingüísticos y culturales específicos de las zonas que quedan fuera de dicha norma ${ }^{45}$.

Así pues, puede decirse que la aparición del diccionario integral de una variedad de lengua tratada previamente como dialectal parece ligada con el intento de superación de un estadio lexicográfico caracterizado por la transcodificación (unidireccional) en el seno de una misma lengua histórica y por los problemas que ello conlleva. Por ejemplo, el de la inseguridad lingüistica motivada por la existencia de unas pautas de corrección parcialmente externas a los usos verbales de una comunidad dada (vid. supra, sobre el francés en Bélgica). Este tipo de diccionario es también, en muchas ocasiones, un instrumento derivado del desarrollo de disciplinas como la política y la planificación lingüísticas y se relaciona con planteamientos previos y habitualmente explícitos de orden ideológico-cultural. Estos últimos han existido en los casos mexicano y quebequense del mismo modo que existieron en la base del primer diccionario de estas características, el American Dictionary of the English Language, el cual vino precedido por una célebre declaración de su autor, N. Webster, dentro de sus Dissertations on the English Language de 1789: "As an independent nation, our honor requires us to have a system of our own, in language as well as government [...]" 46 .

Finalmente, no es desdeñable el interés que para la lingüística y la filología representa la confección de diccionarios integrales (o nacionales). Por ejemplo, de acuerdo con los intereses de la investigación, será posible acometer trabajos contrastivos fiables entre las variedades regionales inter-

45 Vid A.Gallardo (1980), p. 61 y L. Zgusta (1989), pp. 70-72. 46 Citado por M. Görlach (1990), p. 1480. 
nas de cada zona o país y su norma común. Y, lógicamente, también entre las variedades de lengua de distintos países o regiones y no sólo entre la modalidad privilegiada históricamente y el resto, entre las que se establecía la jerarquía general/dialectal. Todo ello sin perder de vista la raíz social del diccionario, lo cual implica la explotación de los conocimientos lingüísticos para construir herramientas de utilidad general. 


\section{BIBLIOGRAFÍA}

AliagA, J.L. (1994): El léxico aragonés en el Diccionario de Autoridades (Real Academia Española), Zaragoza, Institución "Fernando el Católico".

Aliaga, J.L.(1997): "Reseña del Clave. Diccionario de uso del español actual", Revue de linguistique romane, 61, pp. 540-548.

ANDRIANNE, R.(1984): "Belgicismes et canadianismes: pertinence et définition", Cahiers de l'Institut de Linguistique de Louvain, 10/13 , pp. 5-16.

BolléE, A. (1991): "Problèmes de description lexicographique des langues pidgins et créoles", en F. J. Hausmann y otros (eds.), Wörterbücher. Dictionaries. Dictionnaires. Ein internationales Handbuch zur Lexicographie, vol. III, Berlin-New York, W. de Gruyter, pp. 2870-2876.

BOUlANGER, J.C. (1985): "A propos du concept de regionalisme", Lexique, 3, pp. 125-145.

Boulanger, J. C. y J. De Blois (1995): "Reseña de Le Robert junior illustré", Revue de linguistique romane, 59, pp. 599-604.

BraY, L. (1990): "Les marques d'usage dans le Dictionnaire françois (1680) de César-Pierre Richelet", Lexique, 9, pp. 43-59.

Chauveau, J.P. y T. Lavoie (1993): “À propos des origines dialectales du lexique québécois", Revue de linguistique romane, 57, pp. 373420.

CorbeIL, J.C. (1984): "Le «français régional» en question", Cahiers de l'Institut de Linguistique de Louvain, 9/3-4, pp. 31-44.

Corbin, D.: "Le monde étrange des dictionnaires (4): La créativité lexicale, le lexicographe et le linguiste", Lexique, 2, pp. 43-68.

Corbin, D. y P. CoRBIN (1991): "Vers le Dictionnaire dérivationnel du français", Lexique, 10, pp. 147-161.

CORMIER, M. C. (1993): "La lexicographie québécoise à un carrefour: débat autour du Dictionnaire québécois d'aujourd'hui", Cahiers de lexicologie, 63/2, pp. 113-130.

DaOust, D. y J. MauraIS (1987): "L'aménagement linguistique", en J. Maurais (ed.), Politique et aménagement linguistiques, QuébecParis, Conseil de la langue française-Le Robert, pp. 5-46.

DugAs, J. Y. (1983): "La norme lexicale et le classement des canadianismes", en É. Bédard y J. Maurais (eds.), La norme linguistique, Paris-Québec, Gouvernement du Québec-Le Robert, pp. 625-650. 
FORGUE, G. J. (1987): "Les dictionnaires monolingues américains depuis un quart de siècle et le Webster's Third New International; description critique", Lexicographica, 3, pp. 103-141.

FRANCARD, M. (1988): "Autour et alentour du Dictionnaire du français québécois. Les riches heures de la lexicographie québécoise", Le Français Moderne, 56, pp. 246-254.

FrÉCHET, C. y J. B. MARTIN (1993): "Les helvétismes sont-ils tous des traits propres au français de la Suisse romande?", en Études francoprovençales. Actes du $116^{e}$ Congrés national des sociétés savantes, Paris, C.T.H.S., pp. 127-137.

GALLARDO, A. (1980): "Dictionaries and the standardization process", en L. Zgusta (ed.), Theory and method in lexicography: western and non-western perspectives, Columbia, Hornbeam Press, pp. 59-69. GENDRON, J. D. (1986): "Existe-t-il un usage lexical prédominant à l'heure actuelle au Québec?", en L. Boisvert y otros (eds.), La lexicographie québecoise: bilan et perspectives. Actes du colloque organisé par l'équipe de Trésor de la langue française au Québec, Laval, Université de Laval, pp. 89-101.

GILI GAYA, S. (1963): La lexicografia académica del siglo XVIII, Oviedo, Universidad de Oviedo.

GIRARDIN, Ch. (1987): "Système des marques et connotations sociales dans quelques dictionnaires culturels français", Lexicographica, 3 , pp. 76-102.

GöRLACH, M. (1990): "The dictionary of transplanted varieties of languages: English", en F. J. Hausmann y otros (eds.), Wörterbücher. Dictionaries. Dictionnaires. Ein internationales Handbuch zur Lexicographie, vol. II, Berlin-New York, W. de Gruyter, pp. 14751499.

Gútemberg, J. (1984): Concepto de americanismo en la historia del español. Punto de vista lexicológico y lexicográfico, Bogotá, Instituto Caro y Cuervo.

GuTIÉRREZ, J. (1994): “¿Qué puede esperar un hispanista de un diccionario nacional?", en II Encuentro de lingüistas y filólogos de España y México, Salamanca, Universidad de Salamanca-Junta de Castilla y León, pp. 133-152.

HAENSCH, G. (1997): Los diccionarios del español en el umbral del siglo $X X I$, Salamanca, Universidad de Salamanca.

HAUSMANN, F. J. (1986): "Les dictionnaires du français hors de France", en L. Boisvert y otros (eds.), La lexicographie québecoise: bilan et 
perspectives. Actes du colloque organisé par l'équipe de Trésor de la langue française au Québec, Laval, Université de Laval, pp. 3-21. HAUSMANN, F. J. (1990): "Les dictionnaires du français hors de France", en F. J. Hausmann y otros (eds.), Wörterbücher. Dictionaries. Dictionnaires. Ein internationales Handbuch zur Lexicographie, vol. II, Berlin-New York, W. de Gruyter, pp. 1500-1505.

LARA, L. F., dir., (1986): Diccionario básico del español de México, México D. F., El Colegio de México.

LaRA, L. F. (1990): Dimensiones de la lexicografia. A propósito del Diccionario del Español de México, México D. F., El Colegio de México.

LARA, L. F. (1991): "Identidad de usos entre España y América", en Presencia y destino. El español de América hacia el siglo XXI. Encuentro internacional sobre el español de América, vol. I, Santafé de Bogotá, I.C.C., pp. 81-84.

LARA, L. F. (1993): “Crónica de una política del lenguaje abortada: la Comisión para la Defensa del Idioma Español", Iztapalapa. Universidad Autónoma Metropolitana, 29/13, pp. 147-176.

LARA, L. F. (1996): "El Diccionario del español de México como vocabulario dialectal", en I. Ahumada (ed.), Vocabularios dialectales. Revisión crítica y perspectivas. Lecciones del II Seminario de Lexicografia Hispánica, Jaén, Universidad de Jaén, pp. 15-29.

LÁzaro Carreter, F. (1972): Crónica del Diccionario de Autoridades (1713-1740), Madrid, RAE.

LIPȘKI, J. M. (1985): The Spanish of Equatorial Guinea, Tübingen, Niemeyer.

Lope Blanch, J. M. (1969): El léxico indígena en el español de México, México D. F., El Colegio de México.

LOPE BLANCH, J. M. (1972): "El supuesto arcaísmo del español americano", en Estudios sobre el español de México, México, U.N.A.M., pp. 29-49.

LOPE BlANCH, J. M. (1987): "Fisonomía del español de América: unidad y diversidad", Actas del I Congreso Internacional sobre el Español de América, San Juan de Puerto Rico, Academia Puertorriqueña de la Lengua Española, pp. 50-65.

Massion, F. (1987): Dictionnaire de belgicismes, Frankfurt am Main, P. Lang.

MAURAIS, J. (1986): "Régionalismes et langue standard", en L. Boisvert $\mathrm{y}$ otros (eds.), La lexicographie québecoise: bilan et perspectives. 
Actes du colloque organisé par l'équipe de Trésor de la langue française au Québec, Laval, Université de Laval, pp. 79-88.

MERCIER, L. (1992): "Le Dictionnaire du français plus à l'usage des francophones d'Amerique", Cahiers de lexicologie, 60/1, pp. 7183.

POIRIER, C. (1986): "Les avenues de la lexicographie québécoise", en L. Boisvert y otros (eds.), La lexicographie québecoise: bilan et perspectives. Actes du colloque organisé par l'équipe de Trésor de la langue française au Québec, Laval, Université de Laval, pp. 269-285.

REY, A. (1970): "Un texte compromettant: le dictionnaire", Critique, 273, pp. 163-181.

REY, A. (1977): Le lexique. Images et modèles. Du dictionnaire à la lexicologie, Paris, Colin.

REY, A. (1983a): "La lexicographie française: retrospective et perspectives", Lexique, 2, pp. 11-24.

REY, A. (1983b): "Norme et dictionnaires (domaine du français)", en É. Bédard y J. Maurais (eds.), La norme linguistique, Paris-Québec, Gouvernement du Québec-Le Robert, pp. 541-569.

REY, A. (1986): "La variation linguistique dans l'espace et les dictionnaires", en L. Boisvert y otros (eds.), La lexicographie québecoise: bilan et perspectives. Actes du colloque organisé par l'équipe de Trésor de la langue française au Québec, Laval, Université de Laval, pp. 23-40.

REY, A. (1987): "Le dictionnaire culturel", Lexicographica, 3, pp. 3-50.

REY, A. (1990a): "Les marques d'usage et leur mise en place dans les dictionnaires du XVII e siècle: le cas Furetiére", Lexique, 9, pp. 17-29.

REY, A. (1990b): "La lexicographie française depuis Littré", en F. J. Hausmann y otros (eds.), Wörterbücher. Dictionaries. Dictionnaires. Ein internationales Handbuch zur Lexicographie, vol. II, Berlin-New York, W. de Gruyter, pp. 1818-1843.

REY, A. (1992): "Présentation du dictionnaire", en A. Rey y J. ReyDebove (dirs.), Le Petit Robert, Paris, Le Robert, $3^{\mathrm{a}}$ edición.

REY-DeBove, J. (1971): Étude linguistique et sémiotique des dictionnaires français contemporains, The Hague-Paris, Mouton.

Rey-Debove, J. (1994): "La lexicografía moderna", Voz y Letra, 5/1, pp. $31-45$.

SALVADOR, A. (1985): "Las localizaciones geográficas en el Diccionario de Autoridades", Lingüistica Española Actual, 7, pp. 103-139. 
SECO, M. (1988): "El léxico hispanoamericano en los diccionarios de la Academia Española", Boletín de la Real Academia Española, 58, pp. 85-98.

TARKKI, P. (1995): El español en los campamentos de refugiados de la República Árabe Saharaui Democrática, Helsinki, Centro Iberoamericano de la Universidad de Helsinki.

VALDMAN, A. (1983): "Normes locales et francophonie", en É. Bédard y J. Maurais (eds.), La norme linguistique, Paris-Québec, Gouvernement du Québec-Le Robert, pp. 667-706.

WERNER, R. (1991): "Principios diferenciales y contrastivos en la lexicografía del español americano", en Presencia y destino. El español de América hacia el siglo XXI. Encuentro internacional sobre el español de América, vol. I, Santafé de Bogotá, I.C.C., pp. 231-271. ZGUSTA, L. (1989): "The role of dictionaries in the genesis and development of the standard", en F. J. Hausmann y otros (eds.), Wörterbücher. Dictionaries. Dictionnaires. Ein internationales Handbuch zur Lexicographie, vol. I, Berlin-New York, W. de Gruyter, pp. 70-79. 